\title{
Influence of Elevation on Slake Durability Index of Quartz Mica Schist: A Case Study of East Slope of Manjiazhai Open Pit
}

\author{
Yongfeng Lu, ${ }^{1}$ Kepeng Hou $\mathbb{D}^{1},{ }^{1}$ Huafen Sun, ${ }^{1}$ Wei Sun, ${ }^{2}$ Shengyou Zhang, and Jun Jiang ${ }^{1}$ \\ ${ }^{1}$ School of Land and Resources Engineering, Kunming University of Science and Technology, Kunming, Yunnan 650093, China \\ ${ }^{2}$ Yunnan Key Laboratory of Sino-German Blue Mining and Utilization of Special Underground Space, Kunming, \\ Yunnan 650093, China \\ Correspondence should be addressed to Kepeng Hou; luluckyhyf@sina.com
}

Received 30 June 2021; Revised 9 November 2021; Accepted 11 December 2021; Published 12 January 2022

Academic Editor: Tomasz Trzepieciński

Copyright (c) 2022 Yongfeng Lu et al. This is an open access article distributed under the Creative Commons Attribution License, which permits unrestricted use, distribution, and reproduction in any medium, provided the original work is properly cited.

In order to study the influence of elevation on the slake durability index of the quartz mica schist, the quartz mica schist with different elevations on the east slope of the Manjiazhai open-pit mine is taken as the research object, and based on laboratory tests and statistical analysis, the variation of negative correlation between the slake durability index and elevation is obtained. The disintegration mechanism of quartz mica schist at different elevations is also discussed. The test results show that the disintegration characteristics of quartz mica schist at different elevations are related to its mineral composition, fissure channel size, and rock damage effect. As the slope height increases, the ratio of mica to quartz in the rock increases, and the greater the porosity of the rock, the more fissures in the rock, the greater the permeability coefficient, and the more obvious the change of effective stress of rock under osmotic pressure. At the same time, the higher the slope elevation of open-pit mine, the longer the weathering time of rock, the higher the cumulative damage of rock, and the lower the rock slake durability index. This study provides a new idea for guiding the research on the disintegration characteristics of similar soft rock slopes in the elevation direction.

\section{Introduction}

Soft rock is a common rock mass in slope engineering. Under the combined effect of temperature change and rainwater infiltration, the slope rock is prone to weathering and disintegration. This process is characterized by precipitation-evaporation dry-wet cycle effect [1], which causes a significant decrease in the shear strength of rock mass [2] and affects the overall or local stability of slope. Therefore, the collapse characteristics of slope soft rock are directly related to the overall stability of slope and the design of the supporting scheme.

The disintegration of soft rock is a physical phenomenon with complex mechanism. In order to reveal this mechanism, some researchers have carried out tests on rock disintegration to characterize the variation law of the disintegration process under the macroscopic conditions such as the number of cycles, the hydraulic properties, and the mass of disintegration residues $[3,4]$. At the same time,
$\mathrm{X}$-ray diffraction, mercury injection test, and CT scanning were used to study the material composition, fracture propagation degree, and void ratio of soft rock to explain the internal factors of disintegration [5-7].

In terms of the disintegration of soft rock particles, rock disintegration is the result of its internal microcracks continuing to germinate, develop, expand, gather, penetrate, and eventually break into small blocks. This process from microdamage to macrofracture has fractal properties [8]. Therefore, many researchers introduced fractal theory to analyze the particle size change in the process of soft rock disintegration from multiple perspectives, calculated the fractal dimension to describe the disintegration process, and proposed a variety of fractal distribution models based on rock mass [9-11].

Besides, a large number of studies have been carried out on the influence of water change, temperature change, and environmental $\mathrm{pH}$ change on rock disintegration performance in the environment where the rock is located. For example, Huseyin [12] combined freeze-thaw cycles and 
thermal shock to test and study the disintegration resistance of andesite in Turkey. In addition, Deng et al. [13] analyzed the fractal evolution law of rock particle disintegration process under different $\mathrm{pH}$ environments, and it was found that the acidic solution accelerates the growth of particle disintegration fractal dimension.

From the perspective of energy, the disintegration process of soft rock is a process of energy dissipation [14], and the analysis of energy dissipation characteristics can deepen the understanding of rock disintegration and fracture process. Some researchers studied and summarized various ways of energy transfer, transformation, and dissipation in the process of soft rock disintegration, established related energy dissipation models, and pointed out that the change of surface energy leads to rock disintegration $[15,16]$.

The above research studies mainly focused on the influence of chemical composition, structural characteristics, disintegration characteristics, fractal characteristics, and energy angle on rock disintegration characteristics. There are few reports on the influence of elevation on the collapse resistance index of quartz mica schist. Therefore, this paper takes the quartz mica schist on the slope of Manjiazhai open-pit slope as research object and studies the disintegration resistance characteristics of quartz mica schist at different elevations through deterioration test, statistical analysis, and mechanism analysis. The study of rock disintegration characteristics in elevation direction aims at providing valuable researchers on the design of slope stability and protection measures.

\section{Experiment}

2.1. Engineering Geology. Manjiazhai open pit is located in the southwestern border of Yunnan Province, bordering Vietnam, which belongs to subtropical plateau monsoon climate. The rainfall is mostly concentrated from May to October, the maximum rainfall is in July, and the average annual rainfall is $1366 \mathrm{~mm}$. The mining area is a large openpit stope, and the terrain of the east slope is high in the northeast and low in the southwest. The minimum mining elevation is $910 \mathrm{~m}$, the maximum mining elevation is $1360 \mathrm{~m}$, and the maximum elevation difference is $450 \mathrm{~m}$. East slope is artificial slope landform, the maximum slope is as high as $300 \mathrm{~m}$, and the slope is about $39^{\circ}$ with multiple steps' combination. The height of a single step is about $5-30 \mathrm{~m}$, and the slope angle of the step is about $50^{\circ}-70^{\circ}$, as shown in the topographic map of the east slope, see Figure 1. The engineering geological lithology of the slope is complex; as affected by the mining sequence, the weathering degree of the slope is different from top to bottom. The rock mass structure of the east slope is bedding, and the shallow rock mass is dominated by quartz mica schist. In the region, there is a north-south trending $\mathrm{F}_{0}$ fault with a westward dip angle of $40-55^{\circ}$. The upper side of $\mathrm{F}_{0}$ fault is made of quartz mica schist, marble, and skarn, which are widely distributed in various sections of the slope. $F_{0}$ fault footwall is gneiss, as shown in the geological profile of the east slope, see Figure 2. Because the east slope is mainly quartz mica schist, which has low strength, easy weathering, and fracture development, the slope rock mass is very broken, and it is easy to

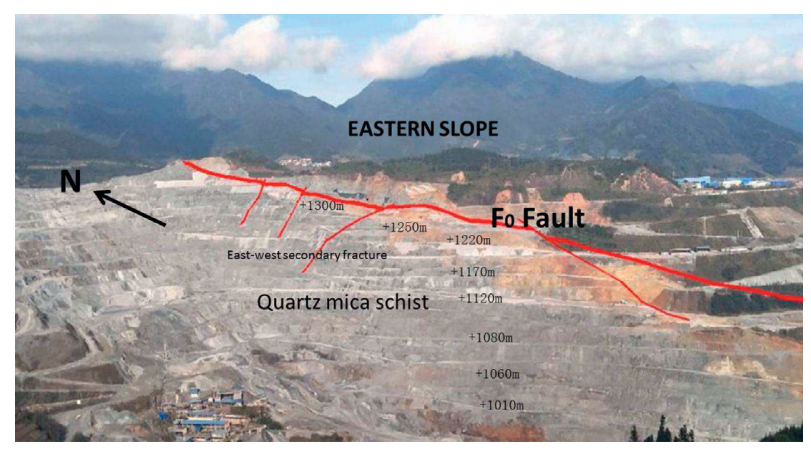

Figure 1: Topography of east slope.

collapse under the influence of rainwater and platform excavation, leading to slope instability.

\subsection{Test Design}

2.2.1. Field Sampling Design. According to the present situation of east slope in Manjiazhai open pit, seven groups of rock samples were selected at the elevations of $1040 \mathrm{~m}$, $1080 \mathrm{~m}, 1120 \mathrm{~m}, 1170 \mathrm{~m}, 1230 \mathrm{~m}, 1280 \mathrm{~m}$, and $1310 \mathrm{~m}$ in the slope profile line position from bottom to top. The collapse resistance test was carried out on these seven groups of rock samples. The schematic diagram of sampling position is shown in Figure 3, and field sampling and test process are shown in Figure 4.

2.2.2. Design of Test Cycles. The slake durability test is a process that rocks are repeatedly disturbed in the dry-wet cycling environment to make rocks reach the disintegration state. This process aims to simulate the real situation of rock experiencing sun and rain under natural conditions. According to the rainfall of Manjiazhai open pit, the annual rainfall in this area is mostly concentrated in July. In this paper, the average total rainfall in July over the years is about $350 \mathrm{~mm}$ [17]. Assuming that each rainfall is $50 \mathrm{~mm}$, the rain number is seven times; thus, seven cycles of indoor slake durability test are set in this paper.

2.3. Research Methods and Results. The rock samples of different elevations were placed in the indoor environment, and the state of rock exposed to sunlight and rain was simulated by the slake durability test instrument. Seven drywet cycles were performed for each rock sample, and the slake durability index was calculated according to [18]

$$
I_{7}=\frac{m_{7}}{m_{0}} \times 100 \%,
$$

where $I_{7}$ is rock (7 cycles) slake durability index (\%), $m_{0}$ is drying quality $(\mathrm{g})$ of the original sample, and $m_{7}$ is the drying quality ( $\mathrm{g}$ ) of residual samples after 7 cycles. The slake durability test results of different elevation samples are shown in Table 1. According to the test results, the relationship curves between the slake durability index $I$ of quartz mica schist and the cycle number $N$ at different elevations of the slope of Manjiazhai open pit are plotted in Figure 5. 


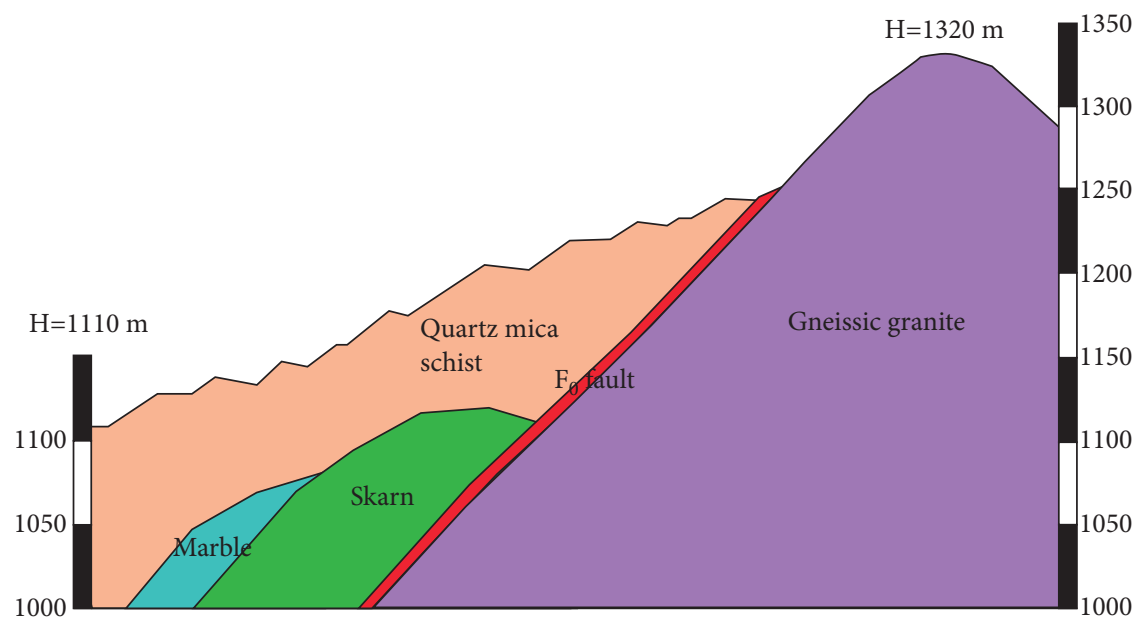

Figure 2: Geological profile of east slope.

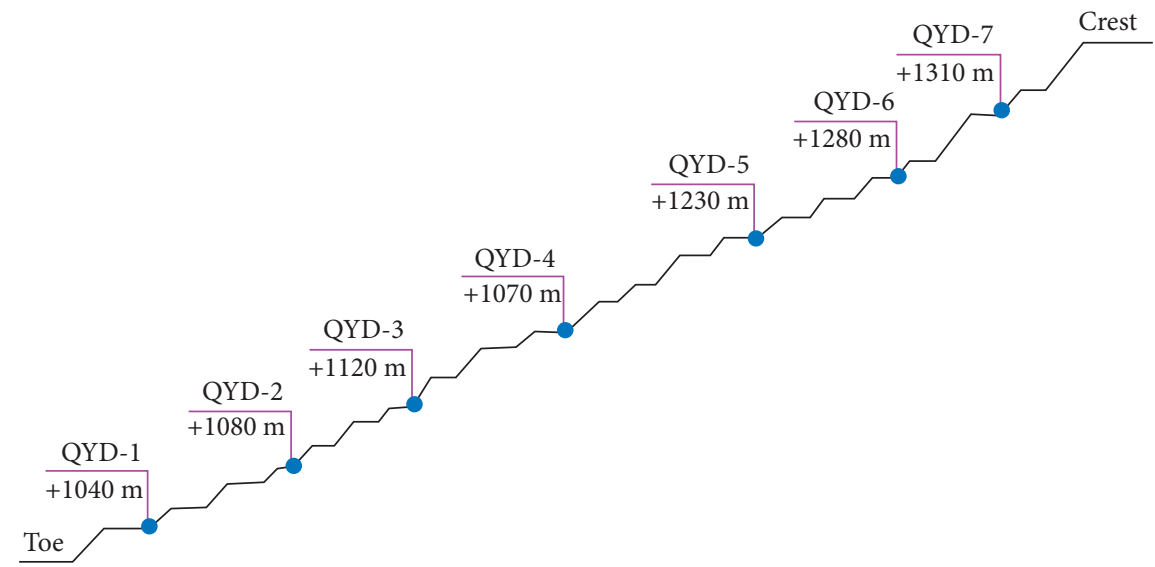

Sampling point location

Figure 3: Sample location diagram.

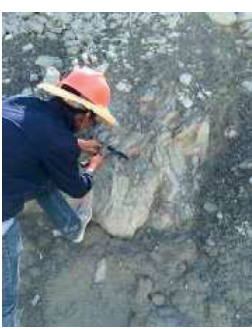

(a)

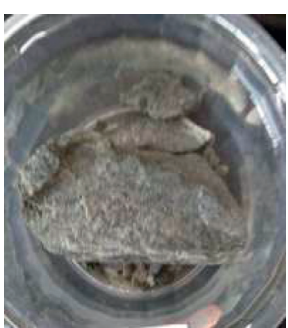

(b)

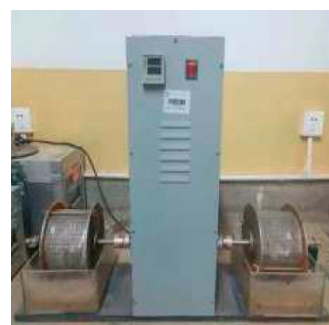

(c)

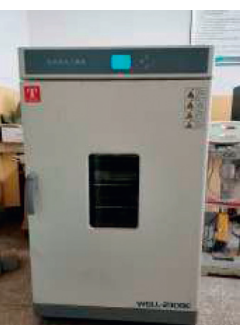

(d)

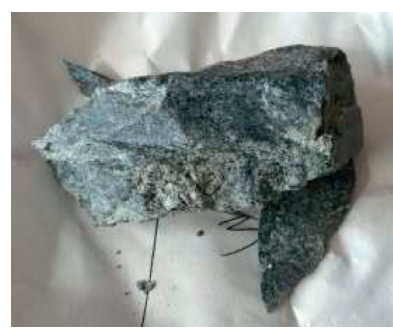

(e)

Figure 4: Test process: (a) field sampling, (b) soaking, (c) collapse resistance test, (d) drying, and (e) post-disintegration residues.

TABLE 1: Test results of rock collapse resistance at different elevations.

\begin{tabular}{|c|c|c|c|c|c|c|c|c|}
\hline \multirow[b]{2}{*}{$\begin{array}{l}\text { Sampling } \\
\text { elevation }(\mathrm{m})\end{array}$} & \multicolumn{7}{|c|}{ Slake durability index under different cycles (\%) } & \multirow[b]{2}{*}{$\begin{array}{l}\text { Lithological } \\
\text { description }\end{array}$} \\
\hline & $\begin{array}{l}\text { The first } \\
\text { cycle }\end{array}$ & $\begin{array}{l}\text { The second } \\
\text { cycle }\end{array}$ & $\begin{array}{l}\text { The third } \\
\text { cycle }\end{array}$ & $\begin{array}{c}\text { The fourth } \\
\text { cycle }\end{array}$ & $\begin{array}{l}\text { The fifth } \\
\text { cycle }\end{array}$ & $\begin{array}{c}\text { The sixth } \\
\text { cycle }\end{array}$ & $\begin{array}{l}\text { The seventh } \\
\text { cycle }\end{array}$ & \\
\hline 1040 & 99.85 & 99.76 & 99.65 & 99.52 & 99.36 & 99.22 & 99.01 & Quartz mica schist \\
\hline 1080 & 99.8 & 99.59 & 99.34 & 99.08 & 98.89 & 98.67 & 98.47 & Quartz mica schist \\
\hline 1120 & 99.7 & 99.21 & 98.76 & 98.34 & 98.02 & 97.66 & 97.54 & Quartz mica schist \\
\hline 1170 & 99.37 & 98.45 & 97.86 & 97.34 & 97.02 & 96.72 & 96.6 & Quartz mica schist \\
\hline 1230 & 98.67 & 98.08 & 97.34 & 96.9 & 96.45 & 96.13 & 96.03 & Quartz mica schist \\
\hline 1280 & 97.95 & 96.91 & 96.26 & 95.76 & 95.26 & 94.51 & 94.42 & Quartz mica schist \\
\hline 1310 & 95.8 & 94.58 & 93.68 & 93.22 & 93.12 & 92.26 & 92.02 & Quartz mica schist \\
\hline
\end{tabular}




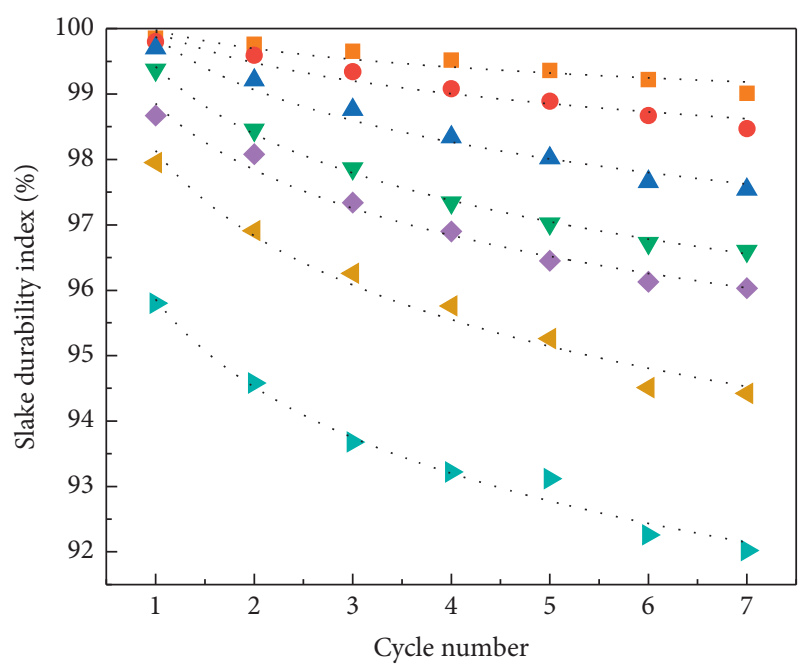

$$
\begin{aligned}
& \text { Curve-fitting Equation } \\
& \text { - } 1040 \mathrm{~m} \text { Elevation sample } \mathrm{y}=99.979 \mathrm{x}^{-0.0041}\left(\mathrm{R}^{2}=0.8259\right) \\
& \text { - } 1080 \text { m Elevation sample } y=99.955 x^{-0.0069}\left(R^{2}=0.9237\right) \\
& \text { - } 1120 \text { m Elevation sample } y=99.875 x^{-0.0117}\left(R^{2}=0.9661\right) \\
& \nabla 1170 \mathrm{~m} \text { Elevation sample } \mathrm{y}=99.419 \mathrm{x}^{-0.015}\left(\mathrm{R}^{2}=0.9965\right) \\
& \text { - } 1230 \text { m Elevation sample } y=98.855 x^{-0.01486}\left(\mathrm{R}^{2}=0.9755\right) \\
& \triangle 1280 \text { m Elevation sample } \mathrm{y}=98.132 \mathrm{x}^{-0.019}\left(\mathrm{R}^{2}=0.9721\right) \\
& \text { - } 1310 \mathrm{~m} \text { Elevation sample } \mathrm{y}=95.861 \mathrm{x}^{-0.020}\left(\mathrm{R}^{2}=0.9798\right)
\end{aligned}
$$

Figure 5: Relationship curves between rock collapse resistance index and cycle times at different elevations.

As shown in the figure, there is a power function relationship between the slake durability index I and the number of cycles $N$, and the correlation is relatively high. The relationship expression is $I_{d}=a N^{-b}$ (where $a$ and $b$ are coefficients). It can be seen that, with the increase of the elevation of the sample at selection position, values $a$ and $b$ are generally reduced. It can be judged from Figure 5 that the higher the elevation is, the lower the slake durability index of the rock sample is, that is, the higher the elevation is, the easier the rock weathering and disintegration are, which may be related to the sequence of excavation time. Besides, the higher the elevation of the slope rock mass is, the longer the exposure time after the elevation excavation is, and the longer the dry-wet cycle is, the lower the slake durability index is.

\section{Statistical Analysis}

According to the test results in Table 1, SPSS [19] software was used to conduct statistical analysis on the variation law of the seventh slake durability index I and elevation $\mathrm{H}$ of quartz mica schist at different elevations on the east slope of Manjiazhai open pit. The results are shown in Table 2, and the following relationship can be obtained from the analysis:

$$
I=(124.36-0.024 \times H) \% .
$$

According to the analysis results,
(1) The coefficient of determination is 0.930 , and the adjusted coefficient is 0.916 . The regression equation has good fitting accuracy.

(2) $P$ value is less than 0.05 , indicating that this regression fitting model has significant statistical significance at 0.05 level.

(3) Elevation has a significant effect on the slake durability index of quartz mica schist, and slake durability index is negatively correlated with elevation.

\section{Mechanism Analysis}

Rock disintegration is closely related to the mineral composition, joint fracture development degree, structural characteristics, and physical and mechanical properties of rock [20]. Because the open-pit slope is composed of multistage bench slope, the exposed time of the upper layer is longer and the exposed time of the lower layer is relatively short after the excavation of the bench slope, resulting in different degrees of weathering of rock at various elevations. At the same time, due to the existence of pores in the rock to form seepage channels, rainwater gradually infiltrates, and the local stress inside the rock changes, producing cumulative damage effect in the rock. Affected by elevation, the development degree of rock pores in various regions is different, and there are differences in seepage path and velocity after rainwater enters. The cumulative effect of rock damage in various regions is different, which eventually leads to different disintegration properties of rock from top to bottom. Therefore, this paper analyzes the influence of elevation on rock disintegration mechanism from three aspects, i.e., the rock material composition, internal fracture channel seepage, and rock cumulative damage.

4.1. Mineral Composition Analysis. Compared with quartz schist, mica schist has significantly severe disintegration, and the particle size of disintegration is also wider. Quartz mica schist is a typical schist, which is distinguished from bedding or layered rock by its unique schistosity structure. In this paper, five kinds of schists with different apparent characteristics were selected, and the results of thin section identification and analysis of the mineral composition of different schists are shown in Table 3 and Figure 6.

It can be seen from Table 3 that, in the mineral composition of quartz mica schist at different elevations, the quartz content is $26 \%-48 \%$ and the mica content is $45 \%$ $60 \%$. In addition, there are also a small amount of altered biotite, sericite, chlorite, and ferritin. According to the identification, the rock has a metamorphic structure, and the matrix has a granular lamellar metamorphic structure. The matrix is mainly composed of the mixed distribution of $0.05-0.2 \mathrm{~mm}$ flake crystalline muscovite, granular metamorphic quartz, and a few sericite and iron argillaceous. The continuous directional arrangement of flake-shaped crystalline muscovite forms the flake structure. Quartz has been fully recrystallized into its granular shape and interbedded in a straight line. 
TABLE 2: Statistical analysis results.

\begin{tabular}{lccccc}
\hline Model & Quadratic sum & Degree of freedom & Mean square & $F$ & Significance probability (p) \\
\hline Regression & 35.438 & 1 & 35.438 & 66.448 & 0.000451 \\
Residual & 2.667 & 5 & 0.533 & \\
Total & 38.105 & 6 & & & \\
\hline
\end{tabular}

Note: $R^{2}=0.930$ and $R_{\text {adjustment }}^{2}=0.916$.

TABLE 3: Main mineral components of quartz mica schist at different elevations.

\begin{tabular}{|c|c|c|c|c|c|c|c|c|}
\hline \multirow{2}{*}{ Sample number } & \multicolumn{7}{|c|}{ Mineral composition and content (\%) } & \multirow{2}{*}{$\begin{array}{c}\text { Ratio of muscovite } \\
\text { to quartz }\end{array}$} \\
\hline & Elevation & Quartz & Muscovite & Chlorite & Altered biotite & Sericite & Iron clay montmorillonite & \\
\hline QYD-1 & 1044 & 48 & 45 & 2 & 3 & 1 & 1 & 0.94 \\
\hline QYD-2 & 1080 & 42 & 50 & 2 & 5 & 1 & Rare & 1.19 \\
\hline QYD-3 & 1120 & 35 & 55 & 3 & 7 & Rare & Rare & 1.57 \\
\hline QYD-4 & 1170 & 33 & 57 & 1 & 4 & 3 & 2 & 1.73 \\
\hline QYD-5 & 1230 & 33 & 60 & 2 & 4 & Rare & 1 & 1.82 \\
\hline QYD-6 & 1280 & 30 & 60 & 1 & 3 & 2 & 4 & 2.00 \\
\hline QYD-7 & 1310 & 26 & 55 & 3 & 8 & 3 & 5 & 2.12 \\
\hline
\end{tabular}

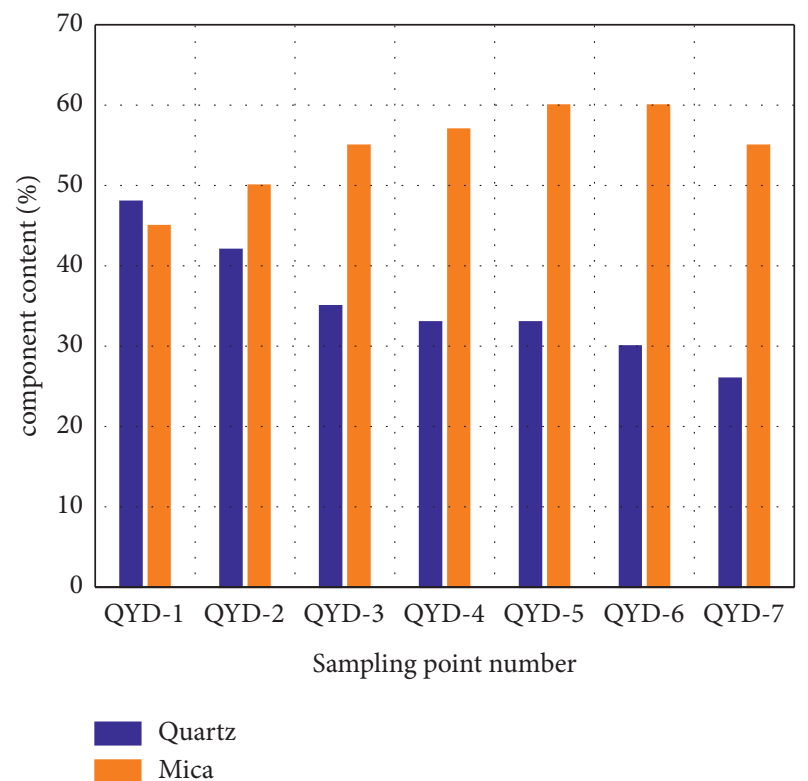

FIgURE 6: Quartz and mica content map at different elevation sampling points.

It can be seen from Figure 7 that, with the increase of elevation, the component content ratio of mica to quartz increases, and because the microcracks in schist are mainly distributed along the edge of mica minerals and affected by the directional arrangement of flake mica, the porosity is proportional to the mica minerals content and the growth scale [21]. Therefore, the higher the elevation, the greater the porosity in quartz mica schist.

4.2. Seepage Analysis of Fracture Channel. The macroscopic failure of rock is mainly based on the change of microfracture interface, and the disordered trajectory of rainwater in the fracture channel leads to the change of the structure size of the microfracture channel. Therefore, the disintegration process of quartz mica schist is microscopically the

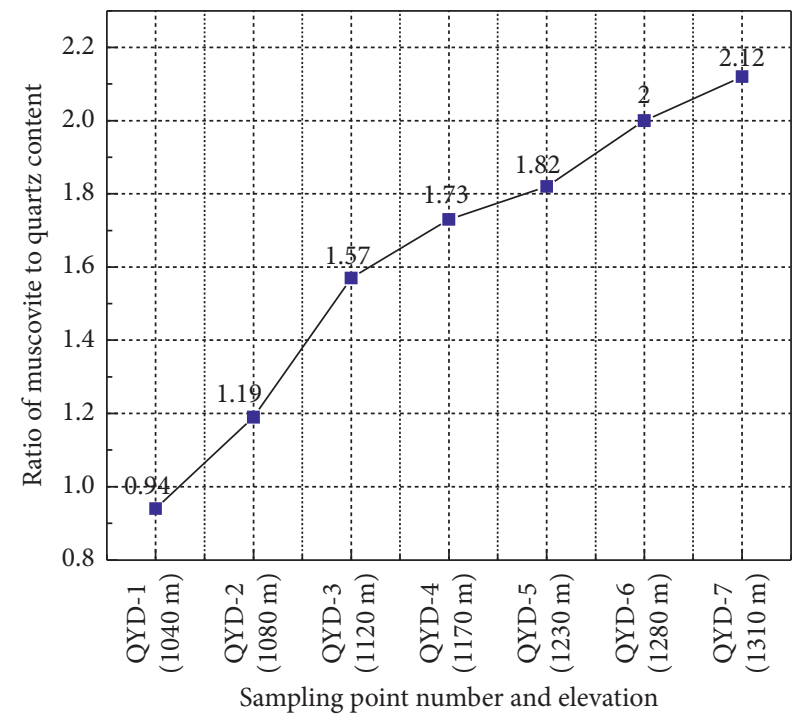

FIgURE 7: The ratio curve of mica and quartz content at different elevation sampling points.

size expansion process of fracture interface in rock, as shown in Figure 8. Microscopically, quartz mica schist is mainly composed of hard parts such as quartz and weak parts such as mica and pore defects [22]. There are a large number of pore defects in the rock, which provides a channel for rainwater to enter the rock. After these complex pore network structures are contacted with water, water molecules are quickly absorbed by the pore defects in the rock, forming pore water pressure. The pore water pressure promotes original cracks' propagation and new cracks' initiation. The pore water pressure reduces the contact force between structural units and promotes the continuous increase of fracture channels $[23,24]$.

As shown in Figure 8(a), the path of microseepage channel inside the rock is random. According to the microstructure of quartz mica schist, the pore channel in the model can be equivalent to the microseepage path. The 


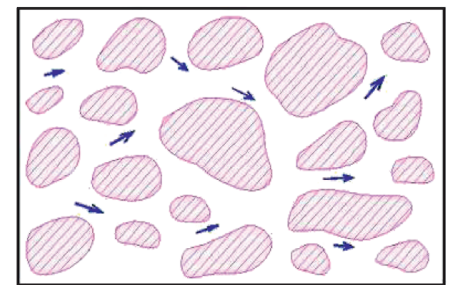

(a)

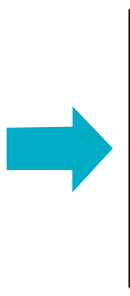

(b)

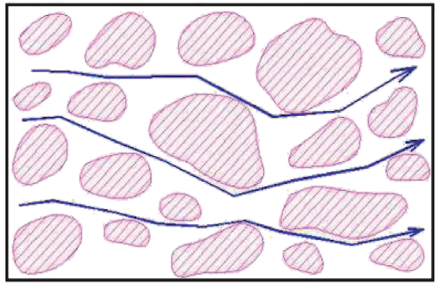

(b)

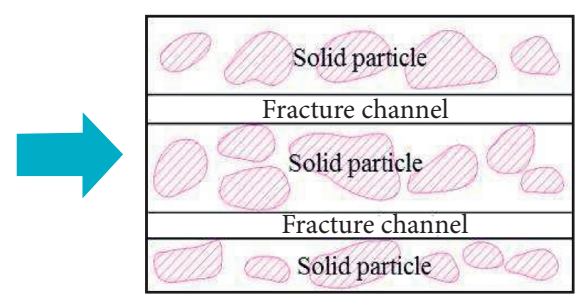

(c)

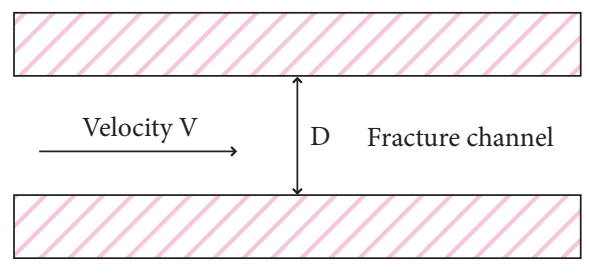

(e)

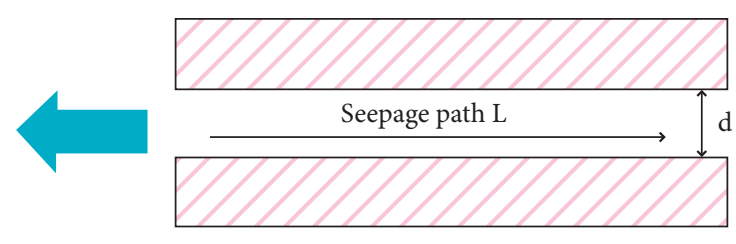

(d)

FIGURE 8: Schematic diagram of crack channel expansion in rock. (a) Water enters rock pore state. (b) Formation of seepage channel. (c) Postgeneralization model. (d) Equivalent fracture channel. (e) Fracture channel widening.

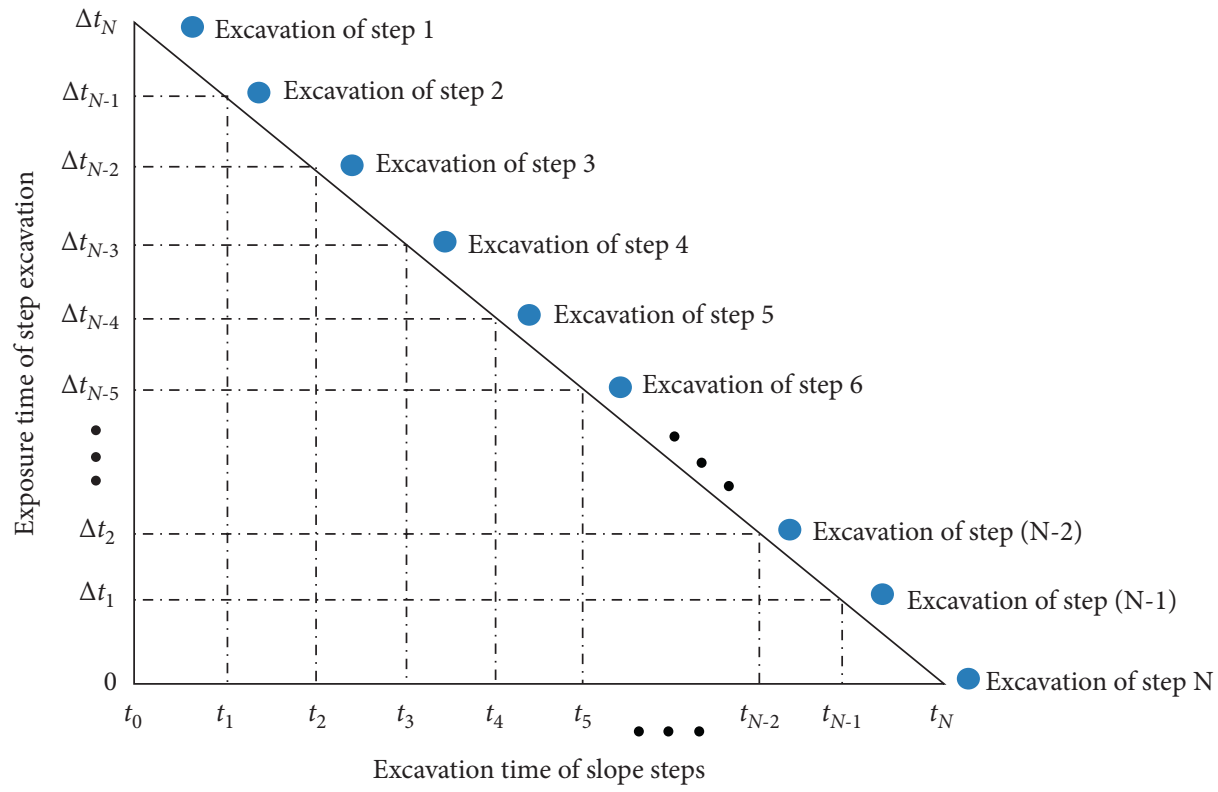

FIgURE 9: Relationship between slope excavation and rock exposure cumulative time.

microparticles are equivalent to two thin plates according to the quartz mica, and the water flows between the two thin plates, as shown in Figure $8(\mathrm{c})$. The pore size of the micropore structure in the rock changes after being subjected to pore pressure, resulting in the change of the liquid flow state. As shown in Figure 8(d), assuming the width of the equivalent fracture channel is $b$, the permeability coefficient of the fracture channel is [25]

$$
k_{f}=\frac{b^{2}}{12},
$$

where $k_{f}$ is the permeability of fractured medium and $b$ is the crack width. For fractured media of rock mass, the permeability coefficient can be expressed as

$$
K_{f}=k_{f} \frac{\rho g}{\mu} .
$$

Replace (4) with (3) to obtain

$$
K_{f}=\frac{b^{2} \rho g}{12 \mu},
$$

where $\rho$ is fluid density and $\mu$ is fluid viscosity coefficient.

Under osmotic pressure, the channel diameter increases from $d$ to $D$ and $K_{f}$ increases to $D^{2} / d^{2}$ times. Because the seepage velocity $v=k i$, where $k$ is the permeability coefficient and $i$ is the hydraulic gradient, as $i=\Delta h / L$, the seepage velocity can be expressed as 


$$
\nu=\frac{D^{2} \rho g}{12 \mu} \frac{\Delta h}{L} .
$$

According to (6), when the other parameters remain unchanged, the seepage velocity increases with the increase of pore width. According to the relationship between rock permeability coefficient and effective stress,

$$
K_{f}=k_{0} \sigma^{-\alpha}
$$

where the permeability coefficient $k_{0}$ is $\sigma=0, \sigma$ is the effective stress, and $\alpha$ is the fractal dimension of fracture distribution density. It can be seen that when the permeability coefficient changes, the effective stress inside the rock will also change.

Through the microscopic fracture seepage analysis of quartz mica schist, the weak structural interfaces such as pore defect channels in the rock are the intrinsic factors leading to rock disintegration, and the pore water pressure is the external power for rock disintegration. Factors such as the expansion of seepage channel size and the acceleration of seepage velocity in rocks eventually cause the disintegration and failure of rocks. Because the weathering degree of rock at various elevations is different, the microfracture development degree and the microfracture permeability coefficient of rock are different, which eventually leads to different rock collapse resistances.

4.3. Analysis of Rock Damage Effect. The sunlight and rain in nature can be characterized by the dry-wet cycle, that is, the rock is affected by the alternation of rain erosion and sunshine drying [26]. This effect will cause damage accumulation to the rock, thus causing the strength degradation of the rock and soil mass on the slope surface. The excavation of the open-pit slope is not accomplished overnight, but follows a certain order, and the slope is excavated from top to bottom. Therefore, the exposure time of the upper bench slope is long and that of the lower part is short, resulting in different time lengths of the slope rock subjected to wet-dry cycling; that is, there is a spatial aging difference in the rock disintegration ability of the same slope from top to bottom. The relationship between slope excavation and cumulative time of rock exposure is shown in Figure 9. Assuming that the weathering time of slope rock is a time series, the time node of the first, second, and $N$ th step is $t_{0}, t_{1}$, and $t_{n}$, respectively, and the exposure time span of each step from top to bottom is $\Delta t_{N}, \ldots, \Delta t_{1}$, that is, the exposure time of the step in nature has the following relationship $\Delta t_{N}>\cdots>\Delta t_{2}>\Delta t_{1}$.

Since the number of cycles $N$ and $(1-D)$ show an exponential relationship, the value of $(1-D)$ decreases with the increase of $N$, where $D$ is the damage factor [27], so $D$ increases with the increase of cycle number $N$. The length of exposure time of rock mass is transformed into number of wetting and drying cycles. According to previous study, the first step has the longest exposure time, that is, the number of cycles of wetting and drying is the largest, and the Nth step has the shortest exposure time and the least number of cycles, that is, $M_{1}>M_{2} \cdots>M_{N}$. According to the relationship between the number of cycles and the damage amount mentioned above, $D_{1}>D_{2} \cdots>D_{N}$.

The ability of rock mass with larger damage accumulation to resist weathering is relatively weak, and it is more sensitive to water, while the expansion effect is gradually enhanced. The earlier exposed rock is, the worse its collapse resistance is [28]. Therefore, in the direction of slope elevation, the difference of rock damage effect leads to regular change of collapse resistance index, namely, $I_{1}<I_{2} \cdots<I_{N}$.

\section{Conclusion}

Taking the multistage combined bench slope of open-pit mining as the research object, the collapse resistance characteristics of quartz mica schist at different elevations are studied by indoor disintegration test, statistical analysis, and mechanism analysis. The conclusions are as follows:

(1) SPSS software was used to conduct statistical analysis on the variation law between the disintegration index of quartz mica schist and the elevation, and the relational expression between the elevation and the disintegration index of quartz mica schist was obtained. There is a negative correlation between the disintegration index and elevation.

(2) Through the identification and analysis of quartz mica schist thin sections at different elevations, it is known that the main mineral components of the rock are quartz and mica, in which the quartz content is $26 \% \sim 48 \%$, and the mica content is $45 \%$ $60 \%$. With the increase of elevation, the ratio of mica and quartz increases, and the porosity of quartz mica schist also increases.

(3) Weak structural interfaces such as material composition and pore defect channels in quartz mica schist are the internal factors leading to its disintegration. Macroscopically, rocks at different elevations are subject to different weathering degrees, resulting in regular changes in local damage of rocks. Under the combined action of multiple factors, the disintegration ability of rocks on the slope surface gradually weakens from the top to the toe of the slope, and the slake durability index is increasing.

\section{Data Availability}

The experimental and theoretical data used to support the findings of this study are available from the corresponding author upon request.

\section{Conflicts of Interest}

The authors declare that they have no conflicts of interest.

\section{Acknowledgments}

The work reported in this paper was financially support by the National Natural Science Foundation of China (no. 51964023). This support is gratefully acknowledged. 


\section{References}

[1] Y. Q. Huang, G. L. Xu, D. W. Zhao, and H. J. Li, "Study on strength deterioration of mica quartz schist under dry-wet circulation," China'S Manganese Industry, vol. 38, no. 3, pp. 33-37, 2020.

[2] X. R. Liu, Y. Fu, Y. X. Wang, L. W. Huang, and X. Y. Qin, "Deterioration rules of shear strength of sand rock under water-rock interaction of reservoir," Chinese Journal of Geotechnical Engineering, vol. 30, no. 9, pp. 1298-1302, 2008.

[3] H. Y. Yao, S. P. Jia, W. N. Gan, Z. H. Zhang, and K. L. Lu, "Properties of crushed red-bed soft rock mixtures used in subgrade," Advances in Materials Science and Engineering, vol. 2016, Article ID 9624974, 8 pages, 2016.

[4] X. H. Liu, J. B. Zhu, P. Zeng, and B. Wang, "Experimental study on the effect of dry-wet cycle on bank slope siltstone," Journal of Yangtze River Scientific Research Institute, vol. 32, no. 10, pp. 74-77, 2015.

[5] Z. Y. Chai, Y. T. Zhan, and X. R. Zhang, "Experimental investigations on correlation with slake durability and mineral composition of mudstone," Journal of China Coal Society, vol. 40, no. 5, pp. 1188-1193, 2015.

[6] N. H. Koralegedara and J. B. Maynard, "Chemical, mineralogical and textural properties of the kope formation mudstones: h," Engineering Geology, vol. 228, pp. 312-322, 2017.

[7] D. Ganesh, Y. Tesuro, K. Masaji, and K. Katsuhiko, "Slake durability and mineralogical properties of some pyroclastic and sedimentary rocks," Engineering Geology, vol. 65, no. 1, pp. 31-45, 2002.

[8] F. Gao, H. P. Xie, and P. Zhao, "Fractal properties and mesostructure effect of rock fragmentation distribution," Chinese Journal of Rock Mechanics and Engineering, vol. 13, no. 3, pp. 240-246, 1994.

[9] Y. H. Su, M. H. Zhao, and X. M. Liu, "Research of fractal mechanism for swelling and collapse of soft rock," Rock and Soil Mechanics, vol. 26, no. 5, pp. 728-732, 2005.

[10] X. Y. Wu, C. W. Liu, K. Zhao, and R. X. Shen, "Research on fractal model of water-immersed collapse of slate," Journal of Sichuan University (Engineering Science Edition), vol. 40, no. 3, pp. 33-36, 2008.

[11] C. Kincal, M. Y. Koca, G. Ozden, and N. Demirbasa, "Fractal parameter approach on weathering grade determination of Çeşme (Izmir, Turkey) tuffs," Bulletin of Engineering Geology and the Environment, vol. 69, pp. 617-629, 2010.

[12] Y. Huseyin, "Effect of freeze-thaw and thermal shock weathering on the physical and mechanical properties of an andesite stone," Bulletin of Engineering Geology and the Environment, vol. 70, no. 2, pp. 187-192, 2011.

[13] T. Deng, M. Huang, and J. W. Zhan, "Fractal evolution law of clay rock disintegration under different $\mathrm{pH}$ conditions," Journal of Tongji University, vol. 42, no. 10, pp. 1480-1485, 2014.

[14] H. P. Xie, R. D. Peng, Y. Ju, and H. W. Zhou, "Energy analysis of rock failure," Chinese Journal of Rock Mechanics and Engineering, vol. 24, no. 15, pp. 2603-2608, 2005.

[15] X. M. Liu, L. Xiong, J. H. Liu, and M. H. Zhao, "Slacking mechanism of red sandstone based on energy dissipation principle," Journal of Central South University (Science and Technology), vol. 42, no. 10, pp. 3143-3149, 2011.

[16] M. Huang and J. W. Zhan, "Disintegration tests and energy dissipation characteristics of soft rock in acid and alkali solution," Rock and Soil Mechanics, vol. 36, no. 9, pp. 2607-2612+2623, 2015.
[17] J. X. Wei, Study on Stability of Soft Rock Slope in East Side Stope of Manjiazhai under Rainfall Infiltration, Kunming U niversity of Science and Technology, Kunming, China, 2017.

[18] B. Liang, Q. Cao, J. G. Wang, and L. G. Jiang, "Experimental study on slaking characteristics of feeble disintegration soft rock in drying-wetting cycle," China Safety Science Journal, vol. 27, no. 8, pp. 91-96, 2017.

[19] Y. R. Cao, "Study on condition applicability of regression analysis based on SPSS weighted regression," Journal of Statistics and Decision, vol. 35, no. 4, pp. 89-92, 2019.

[20] W. Zhang, Y. J. Shang, Y. X. Qu, Y. C. Sun, D. M. Lin, and K. Y. Wang, "Grain size distribution of collapsed scraps of argillaceous rock and its relationship with expansibility:an experimental study," Rock and Soil Mechanics, vol. 34, no. 1, pp. 66-72+79, 2013.

[21] X. M. Yi, E. C. Yan, L. N. Wang, and Y. C. Wang, "Effect of water and microstructure on wave velocity anisotropy of schist and its mechanism," Rock and Soil Mechanics, vol. 40, no. 6, pp. 2221-2230+2238, 2019.

[22] X. K. Fan, "Mechanics of metamorphic rocks in quartz schist area based on micro-test mechanism analysis of characteristic influencing factors," China'S Manganese Industry, vol. 36, no. 5, pp. 24-27, 2018.

[23] Y. Q. Wu and G. Z. Cao, "Permeability experiment of sandstone under variable seepage pressures by using X-ray CT real-time observation," Chinese Journal of Geotechnical Engineering, vol. 7, no. 7, pp. 780-785, 2005.

[24] Y. Zhang and L. Yang, "A novel dynamic predictive method of water inrush from coal floor based on gated recurrent unit model," Natural Hazards, vol. 105, no. 2, pp. 2027-2043, 2020.

[25] W. M. Wang, X. J. Wang, W. S. Zhang, and Z. X. Tian, "Analysis of deformation parameter and permeability coefficient of single fractured heterogeneous rock mass," Journal of Huazhong University of Science \& Technology(Natural Science Edition), vol. 46, no. 10, pp. 40-45, 2018.

[26] Y. Zhou, D. Zhao, B. Li, H. Wang, Q. Tang, and Z. Zhang, "Fatigue damage mechanism and deformation behaviour of granite under ultrahigh-frequency cyclic loading conditions," Rock Mechanics and Rock Engineering, vol. 54, no. 9, pp. 4723-4739, 2021.

[27] X. X. Chen, H. L. Fu, and Z. Qin, "Evolution analysis of rock damage energy of open-pit mine slope under dry-wet circulation," Science Technology and Engineering, vol. 16, no. 20, pp. 247-252, 2016.

[28] F. Li, X. S. Cao, G. W. Li, and J. T. Wu, "Study on the relationship between disintegration and strength of argillaceous soft rock in Yangtze-Huaihe river diversion test project," Journal of Zhi Huai, vol. 485, no. 1, pp. 20-22, 2019. 